\title{
Scleroderma Patients with Pulmonary Artery Hypertension: A Case Report by Muhammad Miftahussurur
}

Submission date: 27-Aug-2019 09:53AM (UTC+0800)

Submission ID: 1163830395

File name: IMRM_2017_81.pdf (246.94K)

Word count: 4980

Character count: 26896 


\title{
Scleroderma Patients with Pulmonary Artery Hypertension: A Case Report
}

\author{
Muhammad Miftahussurur and Joewono Soeroso \\ Department of Internal Disease, Faculty of Medicine, Universitas Airlangga, Dr. Soetomo General Hospital, Jl. Prof dr: \\ Moestopo 47 Surabaya 60132, Indonesia \\ apji@fk.unair:ac.id
}

Keywords: Cellular Immunity, Humoral, Pulmonary Arterial Hypertension, Scleroderma Or Systemic Sclerosis.

Abstract: $\quad$ Scleroderma or systemic sclerosis (SSc) is a multiorgan connective tissue disorder involving the skin, lungs, heart, digestive tract, musculoskeletal system, and peripheral circulation. Pulmonary arterial hypertension $(\mathrm{PAH})$ is an increase in mean pulmonary artery pressure $>25 \mathrm{mmHg}$ as measured by echocardiography or catheterization. The incidence of PAHs with SSc is so rare that reports, in this case, are necessary. Objective: to describe the management of PAH patients with SSc. Case: a 32-year-old patient experiencing PAHs with SSc has stiffness of the mouth and is difficult to open. The ECG shows a sinus tachycardia with a Right axis destination and a cardiomegaly thorax photo with a $64 \%$ cardio-thorax ratio. Some clinical data show autoimmunity. Treatment is oxygen, diuretic, thrombolytic, and immunosuppressive drugs. Conclusions: Reports of PAH treatment with SSC are essential for the improvement of therapy.

\section{INTRODUCTION}

Scleroderma or systemic sclerosis (SSc) is a multiorgan connective tissue disorder involving the skin, lungs, heart, digestive tract, musculoskeletal system and peripheral circulation. SSc is classified by the extent of skin disorders and the presence of other connective tissue diseases, myositis, polyarthritis and systemic lupus 1 erythematosus (SLE). The classification is divided into limited SSc (ISSc), diffuse SSc (dSSc) and overlap syndromes (Madani, Katz, Haddock, Denton, \& Bell, 2008).

Pulmonary arterial hypertension (PAH) is defined as an increase in mean pulmonary artery pressure (mPAP) $>25 \mathrm{mmHg}$ as measured by echocardiography or catheterization (Hill, Preston, \& Roberts, 2008; Picha, Pakas, Guialis, Moutsopoulos, \& Vlachoyiannopoulos, 2008). PAH is a severe complication and is the leading cause of death from SSc $(50 \%)$. Of all cases of connective tissue disease (CTDs) associated with PAH, SSc is the most common case (76\%) (Schachna et al., 2003)

The cause of SSc is still unknown and linked to an autoimmune disease involving cellular and humoral immunity. Cellular, perivascular or diffuse infiltrate is indicated on the skin, lungs (alveolitis), smooth muscle cells, esophagus, ileum and jejunum, synovium and liver consisting of $\mathrm{T}$ lymphocytes (CD4 + and CD8 +), B lymphocytes and other nonspecific inflammatory cells such as macrophages, mast cells and eosinophils. Molecular adhesion and lymphocyte retention and other inflammatory cells in the tissues may provide the role of cellular infiltrate formation in SSC. The mechanism of fibrosis in SSC remains unknown, although it is well-known that soluble mediators (transforming growth factor, platelet-derived growth factor, interleukin-4, interleukin-6, tumor necrosis factor/TNF) may influence the behavior of fibroblast growth, proliferation, collagen synthesis and chemotaxis (Allanore, Avouac, \& Kahan, 2008; Gu et al,, 2008; Sapadin \& Fleischmajer, 2002).

$\mathrm{SSc}$ is associated with increased mortality and morbidity, but there are variations in natural travel. Progression to severe organ attack within 3 years of diagnosis was associated with worsening prognosis with a cumulative 9-year survival rate of $38 \%$ compared to $72 \%$ in patients without extensive organ involvement (Madani et al., 2008). 


\section{CASES}

A 32-year-old female patient (Ny. P) married with a son (5 years old), Javanese, Muslim, elementary school graduate and working as a farmer was hospitalized in the emergency department (ED) of Dr. Soetomo General Hospital Surabaya with the main complaint of shortness of breath. The patient had felt shortness of breath for 2 weeks before being hospitalized and it worsened 1 week later especially with increased activities. However, it improved with rest and she had to sleep with 2 pillows. In addition, she also felt both legs swelling and an enlarged abdomen for 1 week before being hospitalized. There was no occurence of chest pain, heart pounding and fainting.

The patient also complained that her skin had become thickened and stiff all over her body for 12 years without itching and pain, which then turned into a white scar, especially in the back and chest area and did not improve with ointment. In addition, the patient complained of stiffness of the skin of the hands and feet as well as of the face which hampered hand movements and made it difficult for her to open her mouth. The patient also felt changes in the shape of her face. Her fingertips often felt cold and her nails had shrunk. The patient often felt nausea and heat in the chest with decreased appetite for one year before hospitalization. There was no swallowing pain or urinary or eyesight disturbances.

There was the history of skin lesions 8 years ago with scleroderma, and received regular control and oral madecassol $3 \times 20 \mathrm{mg}$, sunscreen and moisturizer. There was also a history of treatment of pulmonary tuberculosis with three negative suspected tuberculosis (TB) of the lung with acidresistant bacteria (BTA) but she had not received anti-tuberculosis drugs (OAT). There was no history of diabetes or high blood pressure. Physical examination results found general weakness, and she was compos mentis. Blood pressure (BP) was 90 $\mathrm{mmHg}$ systolic and $60 \mathrm{mmHg}$ diastolic, pulse 100 times per minute, axillary temperature $36.70{ }^{\circ} \mathrm{C}$, respiration 28 times per minute, and weight $35 \mathrm{~kg}$. Examination of the head and neck showed narowing with increasing JVP. There was no anemia, jaundice and cyanosis, no enlarged lymph nodes and no malar rash or ulcers in the mouth. On chest examination there was no asymmetrical chest movement was found. The examination of the heart found ictus cordis palpable at the $1 \mathrm{~cm}$ midclavicular line sinistra in the 6th gap of the rib. There were normal S1-S2 heart sounds, systolic murmur parasternal line sinistra grade III / VI, no spreading, no extra systole or gallop. On lung examination, a vesicular breath sound with a rough basal rhizome in the inferior third of the lung was found, but wheezing was not found. On abdominal examination, the liver was enlarged $5 \mathrm{~cm}$ below the rib, hepatojugular reflux hepatojugular, non palpable lien and normal bowel sounds. On examination extremities had telangiectasia and pitting edema in the right and left foot. The examination of status localis of the skin of the whole region of the body found macula hyperpigmentation with a borderline that was not firm, some hypopigmentation, palpable thinning atrophy and positive scarring. There were also stiffness and contractures in the fingers and toes and stiffness in the mouth making it difficult to open.

The results of laboratory tests found Hemoglobin (Hb) $13.9 \mathrm{~g} \%$, hematocrites (Hct) $45.2 \%$, leucocytes (Wbc) $5,600 \mathrm{~K} / \mathrm{uL}$, platelets (Plt) $217,000 / \mathrm{ml}$, random blood glucose $78 \mathrm{mg} / \mathrm{dl}$, alanin transaminase (ALT) $24 \mathrm{U} / \mathrm{L}$ and aspartate transaminase (AST) 12 $\mathrm{U} / \mathrm{L}$, albumin $2.1 \mathrm{mg} \%$, blood urea nitrogen 11 $\mathrm{mg} / \mathrm{dl}$, creatinine serum $0.9 \mathrm{mg} / \mathrm{dl}, \mathrm{Na} 136.8 \mathrm{mmol} / \mathrm{L}$ and potassium $3.24 \mathrm{mmol} / \mathrm{L}$. Blood Gas Analysis found $\mathrm{pH} 7.51, \mathrm{PCO}_{2} 25 \mathrm{mmHg}, \mathrm{PO}_{2} 47 \mathrm{mmHg}$, $\mathrm{HCO}_{3} 19.9 \mathrm{mmol} / \mathrm{L}$, BEecf $-3.1 \mathrm{mmol} / \mathrm{L}$ and $\mathrm{SO}_{2}$ $87 \%$. It was concluded that respiratory alkalosis with metabolic acidosis was compensated with severe hypoxia.

The chest $\mathrm{x}$-ray showed an enlarged heart with a $64 \%$ cardio-thorax ratio (CTR) with fibrocalsification in the suprahiler and billateral parahilers, visible fibrosis of the right parahilers, reticular formation of the right paraxial which may be due to widening of the bronchus from adjacent fibrosis, right kostofrenicocostal angle and a dull left, thoracic scoliosis appearing with convexity to the right. It was concluded that there were cardiomegaly, old TB, alleged bronchiectasies, organized right and left pleural effusion, and thoracic scoliosis.

The ECG result found a sinus tachycard rhythm of 115 times per minute with right-axis deviation (RAD) and right ventricular hypertrophy was found. Echocardiographic results showed regurgitation in a moderately heavy tricuspid (TR) valve (Max PG 65 $\mathrm{mmHg}$ ) with the dimensions of the following heart chamber: right ventricular (RV) dilatation, estimation of $80 \mathrm{mmHg}$ pulmonary artery systolic pressure (PASP), normal left ventricle (LV), normal LV systolic function with left ventricular ejection fraction (LVEF) 68\% (by teich), decreased RV systolic function (TAPSE $1.12 \mathrm{~cm}$ ), normokinetic segmental analysis, minimum pericardial effusion 
(PE) in the posterior $0.4 \mathrm{~cm}$, right lateral $0.4 \mathrm{~cm}$ and lateral left $0.34 \mathrm{~cm}$, and no visible thrombus.

A consultation with the Pulmonary Department showed suspected TB. Three BTA examinations were recommended while waiting for mycobacterium tuberculosis (MTB) culture results. Based on the data above, the diagnosis was PAH caused by scleroderma with right heart failure (DC) FC III-IV and hypoalbumin. The patient received therapy with $8 \mathrm{lpm} \mathrm{O}_{2}$ mask, lactated Ringer of 7 drops per minute with $\mathrm{KCl} 25 \mathrm{Meq} / 24 \mathrm{~h}$, a high calorie and high protein diet $(2,100 \mathrm{kcal}), 3 \times 20 \mathrm{mg}$ intra venous (IV) furosemide, beraprost sodium (Dorner) $2 \times 10 \mu \mathrm{g}$ orally, acetyl salicylic acid (ASA) $1 \times 100 \mathrm{mg}$ orally, $20 \%$ albumin given in 6 hours IV and OMZ 2x20 mg IV.

On the second day, the patient complained of shortness of breath and still felt nauseous. Her general condition was weak, compos mentis, systolic blood pressure $80 \mathrm{mmHg}$ and diastolic blood pressure $60 \mathrm{mmHg}$, pulse 100 times per minute, axillary temperature $36.70^{\circ} \mathrm{C}$, and respiration rate 26 times per minute. There were spasms and pitting of the left and right foot and edemas decreased. Laboratory results found potassium $3.2 \mathrm{mEq} / \mathrm{L}$, blood gas analysis showed $\mathrm{pH} 7.51, \mathrm{PCO}_{2} 31$ $\mathrm{mmHg}, \mathrm{PO}_{2} 93 \mathrm{mmHg}, \mathrm{HCO}_{3} 24.7 \mathrm{mmol} / \mathrm{L}$, BEecf $1.7 \mathrm{mmol} / \mathrm{L}$, and $\mathrm{SO}_{2} 98 \%$. It was concluded that the patient had respiratory alkalosis.

She was then referred to the internal disease department which found SSC with hypoalbumin and hypokalemia. The patient received TKCPRG 2,100 kcal therapy, Albumin $20 \%$ in 6 hours, repeated until albumin $>3 \mathrm{~g} / \mathrm{dl}$, KSR $1,200 \mathrm{mg}$ oral. The patient was also advised to have a test for antinuclear antibody (ANA), anti cardiolipin antibody (ACA) and HBsAg and anti-HCV for the preparation of Methotrexate (MTX) and a skin biopsy.

Consultation at the department of genital skin diagnosed the patient with Ssc. It was suggested that if there was no contraindication in TS, madecassol $60 \mathrm{mg}$ oral, Nifedipine $20 \mathrm{mg}$ tablets, Biocream face SPF 15 lotion and $10 \%$ urea could be given. It was concluded that the patient was diagnosed with SSC with PAH and DC right FC III-IV.

On the third day, complaints of tightness decreased and nausea still occurred. Her general condition was weak, and she was compos mentis. Blood pressure 70/palpation, pulse 96 times per minute, axillary temperature $36.80{ }^{\circ} \mathrm{C}$ and respiration 26 times per minute. There were spasms and pitting of the left and right foot and edemas decreased. Re-echocardiography found PASP 85.65
mmHg estimated result and minimal PE appeared. It could be concluded that the diagnoses remained and the patient was given fixed therapy, and only beraprost sodium was reduced to $20 \mu \mathrm{g}$ orally because the BP fell.

On the fifth day the patient felt shortness of breath and decreased nausea. Her general condition was weak, and she was compos mentis. BP 80/50 $\mathrm{mmHg}$, pulse 95 times per minute, axillary temperature $36.70{ }^{\circ} \mathrm{C}$ and breathing 24 times per minute. Laboratory results showed Negative $\mathrm{HBsAg}$ (ELISA) (Abs 0.026 Coff 0.078), Anti HCV (Elisa) Negative (Abs 0.033 C.off 0.413), CRP $12 \mathrm{mg} / 1$ ( $<6 \mathrm{mg} / \mathrm{l}$ ), Potassium $3.0 \mathrm{mmol} / \mathrm{L}, \mathrm{Na} 137 \mathrm{mmol} /$ L. Negative BTA I. Urinalysis: BJ 1.020, PH 5, Leu $500 / \mu \mathrm{l}$, negative nitrite, $25 \mathrm{mg} / \mathrm{dl}$ protein, negative glucose, $5 \mathrm{mg} / \mathrm{dl}$ erythrocytes, erythrocytes $250 \mu$ / $\mathrm{L}$, bilirubin $1 \mathrm{mg} / \mathrm{dl}$, red blood cell sediment, white blood cells sediment, epithelial cells $0-1$, granular positive. It was concluded that the patient's fixed diagnosis was planned for the examination of BTA II and III. Therapy beraprost sodium was raised to $3 \times 10 \mu \mathrm{g}, \mathrm{KCl} 25 \mathrm{Meq}$ in 24 hours, KSR $1,200 \mathrm{mg}$ orally, nifedipine was delayed because the PB was still low, MTX starting $7.5 \mathrm{mg} /$ week, folic acid $3 \times 400 \mu \mathrm{g}$, chloroquin $1 \times 250 \mathrm{mg}$ orally, and other therapy remained. On the $7^{\text {th }}$ day shortness of breath and nausea decreased, with consciousness of compos mentis, BP $80 / 50 \mathrm{mmHg}$, pulse $92 \mathrm{x} / \mathrm{min}$, axillary temperature $36.70^{\circ} \mathrm{C}$ and breathing $24 \mathrm{x} / \mathrm{min}$, and pitting edema of the right and left foot decreased. BTA II and III examination showed negative results. Examination of the esophagogram found no apparent irregularity of the esophageal mucosa, no apparent filling defect or normal esophageal and peristaltic dilatation. The conclusion of the diagnosis remains, the patient planned lung function tests and abdominal ultrasound and fixed therapy. On the $10^{\text {th }}$ day the appetite decreased, compositional consciousness. BP $80 / 50 \mathrm{mmHg}$, pulse $85 \mathrm{x} / \mathrm{min}$, axillary temperature $36.50 \mathrm{C}$, respiration $22 \mathrm{x} / \mathrm{min}$. Laboratory tests showed $\mathrm{Hb} 12.0 \mathrm{~g} \%$, Hct $45.2 \%$, Wbc $4330 \mathrm{~K} / \mathrm{uL}$, Plt 298.000 / ml, ALT 45 U / L and AST $18 \mathrm{U} / \mathrm{L}$, albumin $2.1 \mathrm{mg} \%$, blood urea nitrogen $13 \mathrm{mg} / \mathrm{dl}$, serum creatinine $0.5 \mathrm{mg} / \mathrm{dl}$, Na $133 \mathrm{mmol} / \mathrm{L}$ and Potassium $3.5 \mathrm{mmol} / \mathrm{L}$. The results of Lung physiology found restriction lung abnormalities and severe obstruction with $24.66 \%$ normal vital capillary, $24.66 \%$ normal FCV, $22.23 \%$ normal FEV1, and $16.67 \%$ normal MBC.

Abdominal ultrasound examination gave enlarged liver size readings with homogenous normal parenchymal intensity, flat edges, hepatic vein dilatation, IHBD / EHBD not dilated, invisible 
nodules, cysts or abscesses. It was found free fluid in the abdominal cavity and right-left hemitoraks by echo examination, whereas the kidneys, lien, pancreas, and gallbladder were within normal limits.

On the $12^{\text {th }}$ day, shortness of breath decreased, consciousness was compos mentis, BP 90/60 $\mathrm{mmHg}$, pulse $96 \mathrm{x} / \mathrm{min}$, axillary temperature 36.70 ${ }^{\circ} \mathrm{C}$ and breathing $24 \mathrm{x} / \mathrm{min}$. On consultation with the ophtalmologist was obtained normal ODS fundus and no signs of hypertensive retinopathy. Results of laboratory: IgG ACA negative (index 5.9): (Negative: $<20$ GPL Unit / ml; low Positive 20- $<30$; Positive Moderate 30- $<80$ and High positive $>80$ ), rate of sedimentation of blood (LED) $23 \mathrm{~mm} /$ hour. It was concluded that there was SSc with PAH and DC right FC III. It was planned for the patient to repeat echocardiography and fixed therapy.

On the $12^{\text {th }}$ day the shortness of breath and nausea disappeared, she was compos mentis, BP $90 / 60 \mathrm{mmHg}$, pulse 92 times per minute, axillary temperature $36.80{ }^{\circ} \mathrm{C}$ and respiration 20 times per minute, Hb $11.0 \mathrm{~g} \%$, Hct $45.2 \%$, Wbc $3,900 \mathrm{~K} / \mathrm{uL}$, Plt 223,000/ml, LED $20 \mathrm{~mm} /$ hour. BP $90 / 60 \mathrm{mmHg}$, pulse 92 times per minute, axillary temperature $36.80{ }^{\circ} \mathrm{C}$ and respiration rate 20 times per minute, $\mathrm{Hb} 11.0 \mathrm{~g} \%$, Het $45.2 \%$, Wbc $3,900 \mathrm{~K} / \mathrm{uL}$, Plt 223,000/ml, LED $20 \mathrm{~mm} /$ hour. UL: SG 1.025, PH 5 Wbc $1+$, negative nitrate, negative glucose, negative ketone, bilirubin $1 \mathrm{mg} / \mathrm{dl}$, negative erythrocytes. Red urine blood cell (UBC) sediment, white blood cell (WBC) 0-1 and epithelial cells 1-2. The result of echocardiography showed PASP of $78.26 \mathrm{mmHg}$ with normal LV and normal LV systolic function with LVEF $70 \%$ (by teich). The results of six minutes walk test showed that the patient could walk up to 90 meters. It was concluded that there was SSc with PAH and DC right FC II. The patient was discharged from hospital with Beraprost sodium 30 $\mu \mathrm{g}$ oral therapy, ASA $100 \mathrm{mg}$ oral, oral $40 \mathrm{mg}$ Furosemide, Oral $25 \mathrm{mg}$ spironolactone, MTX 7.5 $\mathrm{mg} /$ week, oral $1,200 \mu \mathrm{g}$ Oral folate. Day 13 test results obtained positive ANA Hep-2 with titer 1: 320 (weak positive). There were also patterns obtained with Hep-2 substrate and ape liver matching with Scl-70 antibody.

On day 10 after discharge, there were back skin PA with epidermal results thinning, and thickened dermis consisting of broad connective tissue connective fibers up to subcutaneous fat. There were little lymphocyte infiltrate and macrophages around the blood vessels. The conclusion was scleroderma.

On the 24th day, MTB culture was negative. On the 30th day of the HRCT examination, it showed fibrosis results in the left lobe of the anterior superior lobe segment, the inferior lingual and the inferior lobes of the apicobasal, lateral and basal postero segments. There was an image of right lung consolidation of the inferior lobe of the lateral, posterior and left lung segments of the inferior lobe of the lateral, posterior, basal segment. There was signet ring segment of the lateral and posterior lobes of the inferior lung lobes both lungs. It was concluded that there were fibrosis process in rightleft lung and bronchiectasies in the lateral and posterior segments of the left lung inferior lobe.

\section{DISCUSSION}

In this patient, the fingertips were often cold and nails narrowed, teleangiectasia nausea and heartburn (3 signs of CREST syndrome) often occurred. There was a history of being treated with scleroderma and scarring mainly in the back and chest area, the skin of the hand and legs felt stiff, there was difficulty to open the mouth and changes in face shape. There were shortness of breath complaints with cardiac and pulmonary involvement and supported by skin PA results supporting the diagnosis of dSSC. Four out of 11 ACR SLE criteria were not found (ANA test was positively weak and $\mathrm{Ig} G$ normal). There was no motor deficit, while $\mathrm{CK}$ and $\mathrm{CPK}$ were not checked.

$\mathrm{SSc}$ is a chronic multisystem disorder characterized by the presence of vascular damage and collagen deposition in various tissues. Three pathological processes contributing to SSC are vasculopathy, inflammation and fibrosis. The American College of Rheumatology (ACR) classifies SSc as Limited SSc (ISSc) if skin involvement is limited to the face and lower extremities (distal from elbows and knees) with normal organ function even though pulmonary hypertension and intestinal malabsorption will develop over time. 1SSc is usually associated with autoimmune diseases such as Sjogren's syndrome or biliary cirrhosis (Allanore et al., 2008). 1SSc often shows signs of CREST syndrome (Calcinosis, Raynaud's phenomenon, Esophageal dysmotility, Sclerodactyly and Telangiectasia) (Madani et al., 2008; Picha et al., 2008). It is classified as diffuse systemic sclerosis (dSSc) if skin thickening occurs proximally from the elbows and knees. In dSSc, the skin of the body (trunk) and upper limb (above the elbows and knees, body or both) are exposed earlier. The patient may experience damage in several organs, especially the kidneys, heart and lungs. If there is a syndrome with overlapping symptoms 
between SSC, SLE, RA and polymyositis then it is included in MCTD (Venables, 2006). This classification helps clinicians to stratify risks in scleroderma patients (Allanore et al., 2008).

ANA Hep-2 test results were positively weak with pattern results with Hep-2 substrate and ape liver matching with Scl-70 antibody. Autoantibodies have been detected in over $95 \%$ of patients with SSc. There are several special SSC autoantibodies that are closely related to type, clinical and prognosis, as shown in Table 1 (Allanore et al., 2008; Picha et al., 2008).

Results of echocardiography showed PASP 80 $\mathrm{mmHg}$, anti Scl-70 positive, HRCT results indicated the presence of fibrosis and bronchiectasis in both lungs with FVC $24.6 \%$. More than $65 \%$ of patients with SSc have pulmonary fibrosis from HRCT examination. Stratification of prognosis is done by linking HRCT and FVC outcomes. If the results of HRCT fibrosis $>20 \%$ and FVC $<70 \%$ then there is a severe lung disorder with a poor prognosis (Goh et al., 2008). Another SSC manifestation of the lung may be bronchiectasis due to fibrosis of the bronchi. Bilateral reticular, alveolitis and/or fibrosis are most common in the pulmonary basal (Korn, 2003).

Table 1: Important autoimmune related to SSc.

\begin{tabular}{|c|c|c|}
\hline Antibody & Usual Subset $^{a}$ & $\begin{array}{l}\text { Clinical } \\
\text { Features }\end{array}$ \\
\hline $\begin{array}{l}\text { Anti-centromere } \\
\text { (ACA) }\end{array}$ & Limited & $\begin{array}{l}\text { PAH, mild- } \\
\text { severe } \\
\text { digestion } \\
\text { impairment }\end{array}$ \\
\hline Anti-Tho/To & Limited & $\begin{array}{l}\text { Interstitial } \\
\text { lung disease } \\
\text { (ILD), PAH }\end{array}$ \\
\hline $\begin{array}{l}\text { Anti- } \\
\text { topoisomerase I } \\
(\mathrm{Scl} 70)\end{array}$ & Diffuse & $\begin{array}{l}\text { ILD, Diffuse } \\
\text { skin } \\
\text { involvement }\end{array}$ \\
\hline $\begin{array}{l}\text { Anti-RNA } \\
\text { polymerase III }\end{array}$ & Diffuse & $\begin{array}{l}\text { Severe skin } \\
\text { disease, } \\
\text { kidney crisis }\end{array}$ \\
\hline Anti-U3-RNP & Diffuse & $\begin{array}{l}\text { Myositis, } \\
\text { heart disease, } \\
\text { PAH, mild } \\
\text { digestive } \\
\text { disorders, } \\
\text { peripheral } \\
\text { neuropathy }\end{array}$ \\
\hline Anti-PM-Scl & Limited & $\begin{array}{l}\text { Heart disease, } \\
\text { kidney crisis, } \\
\text { ILD }\end{array}$ \\
\hline Anti-U1-RNP & Limited & $\begin{array}{l}\text { Heart disease, } \\
\text { kidney crisis, } \\
\text { ILD }\end{array}$ \\
\hline
\end{tabular}
clinically related.
There were right and left pleural effusion, minimal pericardial effusion as well as right heart failure (decreased right ventricular systolic function, increased JVP, liver congestion and foot odema). Pleural effusion occurs in $15 \%$ of MCTD and dSSc patients and is rarely found in SSC patients with no chronic heart failure or pulmonary interstitial disease. Pericardial effusion was also reported in postmortem studies in 31 cases with chronic pericarditis (Thompson \& Pope, 1998). Pleural effusions is often associated with a poor prognosis (Korn, 2003).

There was No Ig G and LED elevations found. Increased LED and IgG occur in SSC patients with PAH. LED is associated with inflammation, anemia and hypergammaglobulinemia, whereas $I g G$ is associated with coagulation due to hyperviscosity. There is no difference in Ig M and IgA between patients with and without PAH (Yamane et al., 2000).

Based on ECG, the result of sinus tachycard rhythm was $115 \mathrm{x}$ / minute with RAD axis, shortness of 2 weeks and light pericardal effusion. There is a suspicion of heart involvement if there are major conduction abnormalities, ventricular arrhythmias, persistent heart failure ( $>2$ months), and moderatesevere pericardial effusions detected by echocardiography. US was not conducted due to device limitations. Involvement of the skin was established through PA examination. In SSc disease, skin is the most affected organ. High-resolution ultrasound (US) is an objective measuring instrument and is able to show the thickening and hypoechogenicity of the affected area (Li, Liebling, \& Haines, 2007).

In these patients, flexion contractures are obtained, with soft tissue atrophy resulting in defects. There were no calcinosis and dystrophic calcification. Flexion contractures, dystrophic calcification and soft tissue atrophy especially in the distal phalanx are common and cause disability. Likewise, hand calcinosis and dystrophic calcification attack tendons, joints, triangular cartilages, intervertebral discs and paraspinal soft tissues. Calcinosis is known from the examination of plain images in the form of ovary tumor-like deposits that surround the joints so as to resemble the wet cotton image (wet cotton-wool).

Esofagogram examination results found no apparent irregularity of the esophageal mucosa, no visible filling defect or dilation or esophageal erosion. Peristaltic was normal. The gastrointestinal tract is the second most common site involved in $\mathrm{SSc}(50 \%)$. The esophagus is most commonly 
affected $(75-90 \%)$, followed by anorectum (50$70 \%$ ), small intestine $(40 \%)$ and colon $(10-50 \%)$. The pathological basis is the presence of fibrosis in the circular layer of smooth muscle, causing motility disorders. Disorders of the esophagus include decreased or loss of peristaltic waves and lower esophageal sphincter strength so that the consequences of gastrooesophageal reflux may predispose patients to distal esophageal stricture, Barrett's esophagus, candida and erosive esophagitis If the process continues, there will be a decrease in upper esophageal sphincter pressure which may increase the risk of aspiration pneumonia (Madani et al., 2008; Sawaf, Orzel, \& Weiland, 1987),

Kidney crisis is a major and specific complication of SSc. There is an acute (within 1 week) $>110 \mathrm{mmHg}$ increase in diastolic pressure and rapid and progressive renal damage associated with hematuria, proteinuria, papillary edema or microangiopathic hemolytic anemia. Antitopoisomerase I and anti-RNA polymerase III antibodies are associated with this complication (Allanore et al., 2008; Penn et al., 2007).

$\mathrm{PAH}$ therapy in $\mathrm{SSc}$ is quite difficult and challenging for clinicians. $100 \%$ oxygen to lower mPAP and diuretics is commonly used to reduce intravascular volume and reduce shortness of breath Some of the specific drugs for PAHs shown in Table 3 include prostacyclin analogs (Epoprostenol (IV), Iloprost (inhalation) and beraprost (oral)), Bosentan (Tracleer), a nonselective endothelin receptor antagonist and Sildenafil (Viagra), phosphodiesterase-5 inhibitor which works through cGMP and cAMP systems (Channick \& Williamson, 2004). The combination of Sildenafil and Bosentan gives good results (Mathai et al., 2007).

Calcium channel blockers (CCBs) inhibit smooth muscle cells to contract by reducing the calcium uptake required for muscle contraction. $\mathrm{CCB}$ of dihydropyridine class, i.e. Nifedipine, is administered in doses of between 30-60 mg daily to reduce the severity of Raynaud's phenomenon Nifedipine therapy can also be combined with platelet anti aggregation drugs such as low-dose aspirin and dipyridamol (up to $400 \mathrm{mg}$ daily) or with Pentoxifylline ( $400 \mathrm{mg}, 3$ times daily) (Sapadin \& Fleischmajer, 2002). The use of small-molecule tyrosine kinase (TK) inhibitors (Imatinib) as inhibitors of platelet-derived growth factor receptor activation as an alternative treatment for SSc is currently developed (Bibi \& Gottlieb, 2008).

The patient was given an oxygen mask, furosemide, spironolacton, beraprost sodium (dorner) up to $3 \times 10 \mu \mathrm{g}$ orally and $1 \times 100$ ASA.
Nifedipine was postponed because the TD tended to be low.

MTx was given starting $7.5 \mathrm{mg} /$ week and $3 \times 400 \mu \mathrm{g}$ folic acid to reduce MTx side-effects. Since there has been evidence that there is activation of humoral and cellular immunity in SSC, several immunosuppressive drugs have been used, including purine antimetabolites (6-thioguanine, azathioprine) and alkylating 13 agents (chlorambucil, cyclophosphamide), methotrexate, cyclosporine, Tacrolimus, cyclophosphamide and extracorporeal photopheresis (Morton \& Powell, 2000; Sapadin \& Fleischmajer, 2002).

This patient had a poor prognosis because of dSSc with $\mathrm{PAH}$, lung involvement and positive antitopoisomerase I antibodies. The prognosis of patients with SSc is 10-year survival rates of 80 $90 \%$ in patients with $1 \mathrm{SSc}$ and $62-76 \%$ in those with dSSc. In one study it was reported that pulmonary and renal involvement in SSC patients and the discovery of antitopoisomerase I antibodies increase mortality. Most deaths are caused by renal crisis, PAH primarily in women and cortexes due to esophageal dysfunction or malabsorption (Jacobsen, Halberg, \& Ullman, 1998).

\section{SUMMARY}

A case of dSSc with PAH has been reported. Diagnosis was made based on several clinical signs, autoantibodies, laboratory tests and was supported by radiological examination. This patient was given a group of Diuretics, Prostacyclin analog and immunosuppressive drugs during hospitalization which resulted in clinical improvement.

\section{REFERENCES}

Allanore, Y., Avouac, J., \& Kahan, A. (2008). Systemic sclerosis: an update in 2008. Joint Bone Spine, 75(6), 650-655. doi: 10.1016/j.jbspin.2008.07.003

Bibi, Y., \& Gottlieb, A. B. (2008). A potential role for imatinib and other small molecule tyrosine kinase inhibitors in the treatment of systemic and localized sclerosis. J Am Acad Dermatol, 59(4), 654-658. doi: 10.1016/j.jaad.2008.04.034

Channick, R., \& Williamson, T. L. (2004). Diagnosis and treatment of pulmonary arterial hypertension. Cardiol Clin, 22(3), 441-452, vii. doi: 10.1016/j.ccl.2004.04.004

Goh, N. S., Desai, S. R., Veeraraghavan, S., Hansell, D. M., Copley, S. J., Maher, T. M., ... Wells, A. U. (2008). Interstitial lung disease in systemic sclerosis: a 
simple staging system. Am J Respir Crit Care Med, $177(11), \quad 1248-1254$. doi: $10.1164 / \mathrm{rccm} .200706-$ $877 \mathrm{OC}$

Gu, Y. S., Kong, J., Cheema, G. S., Keen, C. L., Wick, G. \& Gershwin, M. E. (2008). The immunobiology of systemic sclerosis. Semin Arthritis Rheum, 38(2), 132160. doi: $10.1016 / j$.semarthrit.2007.10.010

Hill, N. S., Preston, I. R., \& Roberts, K. E. (2008) Patients with pulmonary arterial hypertension in clinical trials: who are they? Proc Am Thorac Soc, 5(5), 603-609. doi: 10.1513/pats.200803-032SK

Jacobsen, S., Halberg, P., \& Ullman, S. (1998). Mortality and causes of death of 344 Danish patients with systemic sclerosis (scleroderma). Br J Rheumatol, 37(7), 750-755

Korn, J. H. (2003). Scleroderma: a treatable disease. Cleve Clin JMed, 70(11), 954, 956, 958 passim.

Li, S. C., Liebling, M. S., \& Haines, K. A. (2007). Ultrasonography is a sensitive tool for monitoring localized scleroderma. Rheumatology (Oxford), 46(8), 1316-1319. doi: 10.1093/rheumatology/kem 120

Madani, G., Katz, R. D., Haddock, J. A., Denton, C. P., \& Bell, J. R. (2008). The role of radiology in the management of systemic sclerosis. Clin Radiol, 63(9), 959-967. doi: 10.1016/j.crad.2008.05.007

Mathai, S. C., Girgis, R. E., Fisher, M. R., Champion, H C., Housten-Harris, T., Zaiman, A., \& Hassoun, P. M (2007). Addition of sildenafil to bosentan monotherapy in pulmonary arterial hypertension. Eur $\begin{array}{llll}\text { Respir } & J & 29(3), & 469-475 . \\ \text { doi: }\end{array}$ 10.1183/09031936.00081706

Morton, S. J., \& Powell, R. J. (2000). Cyclosporin and tacrolimus: their use in a routine clinical setting for scleroderma. Rheumatology (Oxford), 39(8), 865-869.

Penn, H., Howie, A. J., Kingdon, E. J., Bunn, C. C., Stratton, R. J., Black, C. M., . . Denton, C. P. (2007) Scleroderma renal crisis: patient characteristics and long-term outcomes. $O J M, \quad 100(8), 485-494$. doi 10.1093/qjmed/hcm052

Picha, L., Pakas, I., Guialis, A., Moutsopoulos, H. M., \& Vlachoyiannopoulos, P. G. (2008). Comparative qualitative and quantitative analysis of scleroderma (systemic sclerosis) serologic immunoassays. $J$ Autoimmun, $\quad 31(2), \quad 166-174 . \quad$ doi: 10.1016/j.jaut.2008.07.001

Sapadin, A. N., \& Fleischmajer, R. (2002). Treatment of scleroderma. Arch Dermatol, 138(1), 99-105.

Sawaf, N. W., Orzel, J. A., \& Weiland, F. L. (1987) Gastroesophageal reflux demonstrated by hepatobiliary imaging in scleroderma. $J$ Nucl Med, 28(3), 387-389.

Schachna, L., Wigley, F. M., Chang, B., White, B., Wise, R. A., \& Gelber, A. C. (2003). Age and risk of pulmonary arterial hypertension in scleroderma. Chest, 124(6), 2098-2104.

Thompson, A. E., \& Pope, J. E. (1998). A study of the frequency of pericardial and pleural effusions in scleroderma. BrJ Rheumatol, 37(12), 1320-1323.
Venables, P. J. (2006). Mixed connective tissue disease. Lupus, $\quad 15(3), \quad 132-137 . \quad$ doi: 10.1191/0961203306lu2283rr

Yamane, K., Ihn, H., Asano, Y., Yazawa, N., Kubo, M., Kikuchi, K.... Tamaki, K. (2000). Clinical and laboratory features of scleroderma patients with pulmonary hypertension. Rheumatology (Oxford), 39(11), 1269-1271. 
Scleroderma Patients with Pulmonary Artery Hypertension: A Case Report

ORIGINALITY REPORT

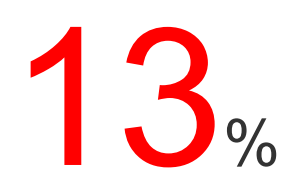

SIMILARITY INDEX

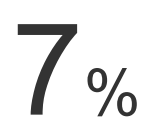

INTERNET SOURCES
$13 \%$

PUBLICATIONS
$0 \%$

STUDENT PAPERS

PRIMARY SOURCES

1

Madani, G.. "The role of radiology in the management of systemic sclerosis", Clinical

Radiology, 200809

Publication

2 jamanetwork.com Internet Source

3 Allanore, Y.. "Systemic sclerosis: an update in 2008", Joint Bone Spine, 200812 Publication

4 www.nature.com Internet Source

5 Textbook of Clinical Pediatrics, 2012.

Publication

6 reumatologi.or.id Internet Source

7 EAPCCT Scientific Committee, . "Abstracts of the European Association of Poisons Centres and Clinical Toxicologists XXII International 
Congress"", Journal of Toxicology Clinical

Toxicology, 2002.

Publication

8

Pines, M.. "Halofuginone to treat fibrosis in

chronic graft-versus-host disease and

scleroderma", Biology of Blood and Marrow

Transplantation, 200307

Publication

9

Purnami Nyilo, Manyakori Serafika Permoni

Putri. "The Association of Reactive Oxygen

Species Levels on Noise Induced Hearing Loss

of High Risk Workers in Dr. Soetomo General

Hospital Surabaya, Indonesia", Indian Journal of

Otolaryngology and Head \& Neck Surgery, 2018

Publication

10 archderm.jamanetwork.com

Internet Source

11 Allanore, Y.. "Treatment of systemic sclerosis", Joint Bone Spine, 200607

Publication

12 scitepress.org

Internet Source

13 Allen N. Sapadin, Raul Fleischmajer. "Treatment of Scleroderma", Archives of Dermatology, 2002 Publication 
15 "Rook's Textbook of Dermatology", Wiley, 2010

16 "Scleroderma", Springer Nature, 2017

17 David Montani, Ari Chaouat. "Diagnostic et classification de l'hypertension pulmonaire", La Presse Médicale, 2010

Publication

$18 \quad 137.200 .4 .16$ Internet Source

19 Ori Elkayam. "Autoantibodies profile of rheumatoid arthritis patients during treatment with infliximab", Autoimmunity, 3/1/2005

Publication

20

Lambova, Sevdalina. "Cardiac manifestations in systemic sclerosis", World Journal of Cardiology, 2014.

Publication

21 www.tsim.org.tw 


\section{Scleroderma Patients with Pulmonary Artery Hypertension: A Case Report}

GRADEMARK REPORT

FINAL GRADE

10

PAGE 1

PAGE 2

PAGE 3

PAGE 4

PAGE 5

PAGE 6

PAGE 7
GENERAL COMMENTS

Instructor 